\title{
Racismo y reconocimiento en una novela de Manuel Zapata Olivella
}

\author{
RACISM AND RECOGNITION IN A NOVEL BY \\ Manuel Zapata Olivella
}

\author{
Luis Ernesto Valencia Angulo \\ Universidad del Pacífico, Buenaventura, Colombia \\ luisva5@yahoo.com
}

Resumen: El presente artículo tiene por objetivo analizar la manera cómo el tema del racismo y el reconocimiento están presentes en una obra literaria de Manuel Zapata Olivella, Chambacú, corral de negros (1963). Desde las primeras líneas, el tema del racismo aparece en esta novela. Es uno de los problemas que ha vapuleado a los afrodescendientes desde tiempos coloniales, sumiéndolos en la miseria, ahogando su cultura ancestral y negándoles sus derechos. En cuanto al reconocimiento, es una inferencia que, como lector e intérprete de su obra, me permito hacer de él a lo largo de las páginas. En la obra se encuentran atisbos valiosos que considero necesario hacer evidentes en este artículo.

Palabras Clave: racismo, reconocimiento, resistencia, yo crítico, afrodiaspórico.

Aвstract: This article aims to analyze how racism and recognition are represented in Manuel Zapata Olivella's literature work of Chambacú, corral de negros (1963). I argue that from the start of the novel, Manuel Zapata 
Olivella deals with racism as one of the main problems that have affected afrocolombians since the colonial times which left a structure that put them into misery, destroyed their ancestral culture, and denied their civil rights. Also, I explore the meaning of recognition in the novel. I think that the storyline of the novel presents valuable glances of how to understand it.

KEYWORDS: racism, recognition, resistance, critical self, African diaspora.

\section{INTRODUCCIÓN}

El presente artículo tiene por objetivo analizar la manera en que el racismo y el reconocimiento son tematizados en la novela Chambacú, corral de negros de Manuel Zapata Olivella. Del fenómeno del racismo se puede aseverar que es una presencia que, de manera directa y consciente, Zapata Olivella introduce como pilar de la denuncia social representada en su novela. En ella se entiende el racismo como el odio, la animadversión de unos seres humanos hacia otros, siendo los rasgos físicos -las diferencias biológicas- la evidencia que permite justificar la supuesta superioridad e inferioridad moral, religiosa, social, cultural, epistémica y económica de unos en relación con los otros. En la novela, a las víctimas del racismo -los afrodescendientes-, en su dimensión cotidiana y sistémica se les deshumaniza por tener vínculo de descendencia con los esclavos de la colonia y se les somete a racialización no solo de su ser, sino también, de su territorio.

El tema del reconocimiento, entendido como la valoración positiva de sí mismos y de los otros que los seres humanos van construyendo en las diferentes dinámicas y esferas de la vida social, es una inferencia que, como lector e intérprete de su obra, me permito hacer. En este sentido, me acerco a Zapata Olivella como se suele hacer con los clásicos en filosofía: para pensar problemas que ellos no habían desarrollado, pero que abordaron en su obra de manera intuitiva, en textos de gran valor para pensar el contexto actual. Será un abordaje somero por dos razones. Primero, porque no se puede decir que en Zapata Olivella haya una teoría del reconocimiento que responde a una tradición filosófica. Segundo, porque, debido a mi formación académica, no pretendo establecer un diálogo literario con otros ensayistas expertos en Chambacú, pues en esta tarea posiblemente fracasaría. Lo que busco es continuar con un 
acercamiento desde la reflexión filosófica, el que me permite sostener que en Chambacú, corral de negros se encuentran atisbos valiosos sobre el tema del reconocimiento que son necesarios hacer evidentes mediante este artículo. Será una contribución modesta pero importante para comprender la gramática de los conflictos morales que afectan a los afrocolombianos y que Zapata Olivella supo denunciar en la producción de sus novelas y ensayos antropológicos y sociológicos.

\section{EL ESCRITOR Y EL CONTEXTO DE LA NOVELA}

Manuel Zapata Olivella (Lorica, 1920-Bogotá, 2004)1 es el intelectual afrocolombiano más prolijo del siglo XX en Colombia. El reconocimiento como intelectual se debe a la variedad de campos y facetas donde se desenvolvió con suma maestría. En este sentido, Zapata Olivella, además de ser médico, fue antropólogo, novelista, ensayista, folclorista, actor, periodista, funcionario público, "vagabundo" -por autodefinición-y activista. Como activista, organizó un sinnúmero de marchas, seminarios y congresos nacionales e internacionales en defensa de los oprimidos, la diáspora africana y del mestizaje. Por esta última noción ha sido criticado, pero, a mi modo de ver, esta debe de ser comprendida como un contraargumento, como una respuesta profunda al discurso y a la ideología de la pureza racial y cultural ${ }^{2}$.

1 De acuerdo con Caicedo, Zapata Olivella pertenece a "una de las familias que más ha aportado desde el arte y la narrativa al pensamiento diaspórico en Colombia. El clan Zapata Olivella, como podría denominarse la existencia de Manuel, Juan y Delia, representa un capítulo trascendental en la vida pública, política, cultural e intelectual de la afrocolombianidad y del país" (302).

2 Un planteamiento similar es el del historiador Santiago Arboleda, quien manifiesta: "Destaca que si el mestizaje es la mezcla racial y cultural, entonces no hay ser humano puro, ya que la experiencia de la especie ha sido el incesante cruce de genes y culturas, por lo que proclama un mestizaje universal, que debe reconocerse, más que continuar negándose en la terca insistencia del colonialismo por clasificar a los seres humanos por el grado de melanina como patrón de poder" (183). Por otra parte, Carlos Valderrama, en un estudio sobre algunas nociones de mestizaje, concibe la noción de mestizaje de Zapata Olivella como una alternativa al mestizaje hegemónico de mitad del siglo XX en Colombia y en América Latina. Una alternativa que implica una estrategia de resistencia sustentada en una agenda antirracista (Valderrama 160). 
No obstante, de la cantidad de facetas de Zapata Olivella, es como escritor de novelas y de ensayos que logra destacar. Con sus trabajos abre un espacio en la memoria intelectual nacional y continental. De su producción como escritor sobresalen algunas novelas, tales como: Tierra mojada (1947), novela en donde lo étnico, la sensibilidad por los desposeídos y la postura crítica frente al discurso oficial son elementos centrales; Pasión vagabunda (1949), obra inspirada en su experiencia de discriminación racial padecida en los Estados Unidos; La calle 10 (1960), novela urbana de denuncia, en ella recrea los sucesos del bogotazo; Detrás del rostro (1962), en la que detalla aspectos de la vida urbana y rural a partir de las vivencias de un niño perdido y con la que ganó el Premio Literario Esso, otorgado por la Academia Colombiana de la Lengua; Chambacú, corral de negros (1963), -novela de la que hablaremos más adelante-; En Chimá nace un santo (1964), novela en la que se cuenta la historia de un "tullido" milagrero, cuyos "poderes", al morir, son objeto de controversia y se convierten en fuente de esperanza para los oprimidos y la cual resultó finalista en dos concursos: el Premio de Novela Breve Seix Barral de Barcelona de 1962, que fue otorgado a Mario Vargas Llosa, y el Esso de 1963, ganado finalmente por Gabriel García Márquez; Changó, el gran putas (1983), novela mítica que cuenta la experiencia de la diáspora africana en América. Esta última es considerada por muchos como su novela más importante y por ella se le otorgó el Premio Francisco Matarazzo Sobrinho en 1985. Entre sus ensayos más destacados están: Las claves profundas (1982), Etnografía colombiana (1984), La Costa Atlántica (1984), Nuestra voz: aportes del habla popular latinoamericana al idioma español (1987), Las claves mágicas de América (1988), ¡Levántate mulato! Por mi raza hablará mi espíritu (1990), por el que ganó el premio "Nuevos Derechos Humanos", otorgado por la Asamblea Nacional de Francia; y La rebelión de los genes. El mestizaje americano en la sociedad futura (1997).

De la vida como "vagabundo" vale destacar dos momentos pertinentes al tema de interés. El primero se relaciona con su aventura de recorrer Centroamérica de diversas formas, "unas veces a pie, otras en chiva, otras 'a dedo', en automóviles y camiones” (Díaz 242). Al llegar a Guatemala, debido a las circunstancias, le tocó desempeñar por algún tiempo el oficio de boxeador, momento en que se da a conocer con el epíteto de "Kid Chambacú" (ibid.), sobrenombre que años después introduce en un bello fragmento de Chambacú, corral de negros, como 
muestra de su habilidad narrativa y de esa riqueza de vivencias que el "vagabundaje" le permitió atesorar con el paso de los años. El segundo momento tiene que ver con su llegada a Estados Unidos. Su importancia no radica, como muchos han señalado, en el conocimiento directo que adquirió de la atroz discriminación racial (ibid.), sino, más bien, en el común sufrimiento que los afrodescendientes padecen en el continente americano, con sus particularidades contextuales, pero con la tribulación habitual que caracteriza a la diáspora africana en América.

Chambacú, corral de negros (1963), novela por la que obtiene una mención en el Premio Casa de las Américas en La Habana en 1963, surge en el contexto del boom literario latinoamericano, esto es, entre la década de 1960 y $1970^{3}$. Un contexto caracterizado por un clima de gran dinamismo sociopolítico que repercutió en la escritura de los jóvenes novelistas de este momento. La Guerra Fría, La Revolución cubana y los efectos de la Guerra de Corea se constituyeron, en gran medida, en el cimiento del trabajo literario de los novelistas de este contexto. Dichos eventos alimentaron sus posturas políticas, entregaron argumentos e ilustraciones que justificaron y enriquecieron sus compromisos ideológicos, sus destrezas descriptivas y sus espíritus críticos. Espíritus con

Frente a la relación de Manuel Zapata Olivella con el boom literario latinoamericano, hay posturas encontradas. Por ejemplo, Caicedo muestra a un Zapata Olivella por fuera del boom literario latinoamericano, cuyas producciones (en sus años de mayor esplendor, la década de los setenta y ochenta) en gran medida postergaron y opacaron el brillo de una novela como Changó, el gran putas: "En la novela se propone una temporalidad esencialmente africana, poniéndola en un lugar de alteridad para la narrativa de la época en la que se produce, y que se ve opacada por la supremacía del boom literario Latinoamericano, hecho que obstaculizó, en parte, su divulgación y recepción en sus justas proporciones" (Caicedo 313-314). Por otra parte, Díaz parte de una ubicación temporal diferente a la de Caicedo: los años de esplendor del boom literario latinoamericano serían la década de los sesenta y setenta. En esta temporalidad, Díaz ubica a Zapata Olivella como uno de los escritores colombianos destacados dentro de este movimiento literario: "En esa época se destacaron novelas como: El coronel no tiene quien le escriba, La mala hora y Cien años de soledad del mundialmente célebre Gabriel García Márquez; En Chimá nace un santo, Chambacú, corral de negros, y Detrás del sol, de Manuel Zapata Olivella; La rebelión de las ratas, de Fernando Soto Aparicio; Respirando el verano y En noviembre llega el arzobispo, de Héctor Rojas Herazo; El día señalado, de Manuel Mejía Vallejo; El hostigante verano de los dioses, de Fanny Buitrago; El buen salvaje, de Eduardo Caballero Calderón" (Díaz 22-24). 
los que desafiaron no solo las convenciones literarias establecidas en Latinoamérica, sino también a los gobiernos políticos de turno. Actitud que, en muchas ocasiones, los llevó a la cárcel y al exilio. Como resultado de lo anterior, se da otra de las características del boom literario: las obras de estos jóvenes escritores empiezan a ser publicadas y traducidas en todo el mundo, en especial, en Europa.

Estas características están todas presentes en Manuel Zapata Olivella ${ }^{4}$. Su espíritu crítico -además de llevarlo a la cárcel en el gobierno del ultraconservador Laureano Gómez, bajo la acusación de traición a la patria por estar en contra de la intervención de Estados Unidos en Corea (Díaz 245) - lo mueve a configurar la denuncia presente en su Chambacú, corral de negros contra las intenciones de la policía colombiana de reclutar jóvenes negros de Chambacú para que lucharan junto al ejército estadounidense en contra de los comunistas en Corea. De igual forma, Chambacú, corral de negros representa la ruptura con el convencionalismo literario, pues, en continuidad con Candelario Obeso y Jorge Artel, logra crear una narración en la que la voz del afrocolombiano, su intimidad y su existencia se constituyen en el centro de su creación. Aquí no hay mediación, no es la voz del blanco, del europeo que traduce al afrocolombiano, es el mismo afrocolombiano quien habla, quien coloca su voz en "el concierto universal de las voces", desnudando sus valores, su sentir y su cosmovisión.

En este libro, Zapata Olivella ya ha logrado lo que denunciará más adelante en uno de sus ensayos: salirle al paso a la ceguera alienante presente en el escritor latinoamericano, la cual "se refleja en su pensamiento, lenguaje y en la interpretación de la realidad y la historia novelada" (Zapata, "Descolonización” 143). Se entiende que después de tanta brutalidad desplegada en la forma de genocidio, violaciones sexuales, racismos y linchamientos durante la colonia, el latinoamericano no podía salir ileso. De ahí que, en muchos de los escritores, los complejos de superioridad e inferioridad, la vulgar imitación y la falta

4 Para William Mina Aragón, la producción literaria de Zapata Olivella ubicada en la década de los sesenta, "no hace otra cosa que lo que hacen los de su generación: analizar lo urbano, describir lo social, centrarse en la novela psicológica y en describir los problemas de marginación, pobreza, de exclusión social y hacerle una crítica al imaginario del poder político [...] ¿ ¿será que la razón de la exclusión de $\mathrm{MZO}$ del Boom fue porque sus personajes eran esencialmente afro y amerindios?" (Mina 53). 
de rigor en el ejercicio de la crítica literaria afectaran la configuración de la imagen de los personajes en sus obras. Según Zapata Olivella, cuando estos personajes eran afrodescendientes, se creaba una imagen distorsionada en doble sentido, o por la vía de la barbarización o por la vía de la superposición de los valores europeos.

Ceguera alienante, que, como bien señala Caicedo, había llevado a que los escritores afrodescendientes latinoamericanos estuviesen atrapados "en las concepciones negristas, piezas literarias estereotipadas que rendían culto a la exageración de los vocablos negros, la alienación del lenguaje y el control ejercido por la Real Academia de la Lengua, que se opuso al uso de los vocablos surgidos en América" (307). Se trata de un problema identitario en que el racismo y la falta del debido reconocimiento hacen su presencia, en el sentido en que las piezas literarias refuerzan una imagen negativa, estereotipada de lo afro.

Es en el marco del esfuerzo por contrarrestar estos problemas, que se puede interpretar la influencia del movimiento de la négritude en Zapata Olivella. Como señala Aldana (7), desde los años sesenta, periodo de publicación de la novela Chambacú, corral de negros, la négritude era parte del imaginario de Zapata Olivella. La négritude está presente en el universo de la novela, los personajes afrodescendientes encarnan una franca lucha por los derechos humanos básicos y la necesidad de tener un reconocimiento pleno de la ciudadanía. De igual forma, la influencia de los principios del movimiento de la négritude fue clave para que Zapata Olivella creara una contraestética a la tendencia literaria hegemónica de los sesenta, presente en el boom literario latinoamericano. Mientras los autores que se destacaban en esta tendencia han sido clasificados como mágico realistas o surrealistas (Aldana 7), la producción de Zapata Olivella hasta esa década era una novela social realista en la que se denunciaba la exclusión social padecida por los afrodescendientes.

En el diálogo que Zapata Olivella tuvo con los representantes más destacados de la negritud ${ }^{5}$-como lo fueron Léopold Sédar Senghor, Aimé Césaire, Léon Damas, entre otros- fue fortaleciendo su idea de propender por una literatura crítica en la que se reconozca a África en América. Este reconocimiento implicaba ver dos continentes nuevos,

5 Un ejemplo de este diálogo fue la participación de Zapata Olivella en el encuentro convocado por Sédar Senghor, Diálogo de la Negritud y la América Latina, en Dakar en 1974 (Zapata, ;Levántate mulato! 337). 
trasformados, enriquecidos por el mestizaje y el acervo de las luchas que los afrodescendientes han dado por la libertad. Aunque en Chambacú, corral de negros se evidencia el diálogo con los principios del movimiento de la négritude, es ;Levántate mulato!: por mi raza hablará el espíritu un texto en que Zapata Olivella desarrollará de manera profunda la relación con este movimiento literario y sus principios ${ }^{6}$.

\section{El RACISMO Y RECONOCIMIENTO EN CHAMBACÚ, CORRAL DE NEGROS}

Chambacú es una comunidad creada por afrodescendientes a principios del siglo XX, ubicada al lado de las murallas que rodean a Cartagena. Llegó a ser definida como "el más grande y antiguo tugurio del país" (Cunin 135). Por su ubicación, a principios de los años setenta, Chambacú se convirtió en un escollo para el desarrollo de los proyectos urbanísticos y turísticos de Cartagena, constituyéndose en la justificación "adecuada" para una insensible erradicación. Hecho que permite recordar a Chambacú en la historia de Colombia de dos formas. La primera, como uno de los casos de corrupción más sonados de ese momento, pues, en los años siguientes, el nombre Chambacú se vinculó a un estruendoso caso de corrupción debido a problemas relacionados con desviación de fondos, tráfico de influencias y desaparición de documentos administrativos (Cunín 136-137; Ortiz 96). Problemas legales y éticos que hicieron que los proyectos urbanísticos bajo los que se justificó el desalojo no

6 Libro autobiográfico, publicado en 1990, en el que Zapata Olivella da muestra de un profundo conocimiento de la configuración de los procesos culturales e identitarios que han dado forma a la diversidad étnica y cultural de Colombia, en particular, y de Latinoamérica, en general. Conocimiento en el que la influencia del movimiento de la négritude está presente: "América se negreó con los africanos, no por su piel negra, sino por su rebeldía, sus luchas antiesclavistas, su unión con el indio para combatir al opresor, por sus tambores y orichas guerreros, por sus pregones, por su músculo; por su inquebrantable optimismo de pueblo vencedor. [...] Mestizaje contra racismo ha sido siempre la fórmula de la vida contra las sociedades clasistas en la historia de todos los pueblos en el mundo. Con estos presupuestos nacidos de la cultura triétnica de nuestro país, dimensión extendida a la mayor parte de los pueblos de América, mi hermana y yo hemos acogido con decisión los vientos de la negritud" (Zapata, ;Levántate mulato! 334). 
se concretaran, dejando por treinta años en el abandono un inmenso territorio otrora habitado por seres humanos que vivían en condiciones de extrema desigualdad económica. La segunda, es que Chambacú simboliza esa memoria, esa historia de racismo -y racialización del espacio-y resistencia que afrocolombianos han vivido en el desarrollo de una de las ciudades más emblemáticas de Colombia, Cartagena. Esta última forma de recordar a Chambacú está presente en la novela de Manuel Zapata Olivella.

Nuestro autor introduce el tema del racismo en Chambacú, corral de negros desde las primeras líneas: "Galopaban las botas. Producían un chasquido que antes de estrellarse contra las viejas murallas ya se convertían en eco. Los carramplones de la caballada humana resonaban fuertes. Sombras, polvo, voces. Despertaban a cuatro siglos dormidos" (Zapata, Chambacú 27).

"Cuatro siglos dormidos" es una alusión directa al colonialismo. Para Zapata Olivella, Chambacú encarna dos de las manifestaciones de la dominación colonial en el continente americano: la africanidad y el racismo. La africanidad es una herencia histórica que, a lo largo de su carrera, Zapata Olivella decide destacar como uno de los componentes constitutivos de la plurietnicidad de Colombia y del continente. Herencia, a su parecer, digna de ser protegida y preservada, porque en ella hay unas valiosas enseñanzas en términos de resistencia, esperanza y creatividad. Zapata Olivella va destacando estos valores a lo largo de la trama de la novela. Me iré refiriendo a ellos de manera directa e indirecta en relación con el fenómeno del racismo y el reconocimiento.

La africanidad y el racismo como herencia histórica colonial que se rehace, se vivifica en la suerte de Chambacú. Esta herencia alimenta el pensamiento y las palabras de Máximo, el protagonista de la novela, quien en un diálogo expresa:

Tu presencia nos hace sentir extraños. No es debido a la diferencia de piel. Nos revela nuestras limitaciones culturales. Vejados por la miseria, ni siquiera los instintos pueden realizarse normalmente. Pero no solo somos un saco de apetitos contenidos. Nuestra cultura ancestral también está ahogada. Se expresa en formas mágicas. Supersticiones. Desde hace cuatrocientos ańos se nos ha prohibido decir "esto es mío". Nos expresamos en un idioma ajeno. Nuestros sentimientos no encuentran todavía las palabras 
exactas para afirmarse. Cuando me oyes hablar de revolución me refiero a algo más que romper ataduras. Reclamo el derecho simple de ser lo que somos.

[...] No es ocasional que Chambacú, corral de negros, haya nacido al pie de las murallas. Nuestros antepasados fueron traídos aquí para construirlas. Los barcos negreros llegaron atestados de esclavos provenientes de toda África. Mandingas, yolofos, minas, carabalíes, biáfaras, yorubas, más de cuarenta tribus. Para diferenciarlos marcaban las espaldas y pechos con hierros candentes (Zapata, Chambacú 189).

Máximo es lo que llamaré el yo crítico $^{7}$ de la novela. Es el personaje que se constituye como parte fundamental del conflicto, en la medida en que plantea una tensión ética con su entorno social cartagenero, ya que lo veja, le niega el reconocimiento de su ancestralidad, de su ser, su voz. En definitiva, niega lo fundamental por la vía del racismo. Para Máximo, la gloria, el esplendor de una ciudad como Cartagena, se ha construido gracias al aporte capital de los negros. Sin duda alguna, es a través de este personaje que Zapata Olivella confronta el racismo. Un racismo que vapulea a los afrodescendientes sumiéndolos en la miseria, ahogando su cultura ancestral y negándoles sus derechos.

Ser negro es la razón del odio. A partir de este "hecho" comienza el gran problema de los negros en la novela, el menosprecio padecido, y, de igual forma, de los afrodescendientes en la realidad de Colombia y del continente americano. Entonces, ¿qué significa ser negro? En la novela hay diferentes pasajes que dan pistas para abordar esta interrogante:

Concepto que utilizo apoyado en la argumentación psíquica relacionada con el análisis de los trabajos de George Mead, presente en la teoría del reconocimiento de Axel Honneth. Lo que denomino yo crítico comparte con esta teoría la idea de destacar el papel que tienen "las personalidades carismáticas", las grandes figuras que, por el papel que desempeñaban en la comunidad, supieron ensanchar el perímetro de los derechos, la autonomía, la calidad de vida de esta, de acuerdo con las expectativas intuitivas de sus contemporáneos (Honneth 106). Máximo reúne cada uno de estos elementos, es un yo crítico en el sentido de ser una gran figura, un personaje carismático que dentro de la comunidad sabe captar sus expectativas, está en la capacidad de impulsar su transformación, enriquecerla y ampliarla. No obstante, Máximo, a diferencia de otras grandes figuras o personajes carismáticos, es un yo crítico que está constituido por la experiencia diaspórica colonial. 
— ¡Negro asqueroso! ¡Si vienes con tus groserías nos vamos! No te creas que porque te has comprado una botellita de whisky, tienes derecho a ultrajarnos (Zapata, Chambacú 111).

-Otra vez te tengo aquí, pero ahora la vaina es en serio. No se trata de que hayas empujado a los de la isla a invadir terrenos ajenos. Te has puesto a contradecir el mandato de las Naciones Unidas. ¡Tú, un pobre negro! (Zapata, Chambacú 66-67).

—La isla crece. Mañana seremos quince mil familias. El "Cáncer negro", como nos llaman. Quieren destruirnos. Temen que un día crucemos el puente y la ola de tugurios inunden la ciudad. Por eso para nosotros no hay calles, alcantarillados, escuelas ni higiene. Pretenden ahogarnos en la miseria. Se engañan. Lucharemos por la dignidad de seres humanos. No nos dejaremos expulsar de Chambacú. Jamás cambiarán el rostro negro de Cartagena. Su grandeza y gloria descansa sobre los huesos de nuestros antepasados (Zapata, Chambacú 197-198).

Según estos pasajes, ser negro significa ser reducido a la condición de lo no humano, a un subhumano, una cosa, una bestia, un cáncer. Este es el punto de partida del odio, del racismo en la novela. Los habitantes de Chambacú son negros, son la continuidad de los esclavizados. Máximo es consciente de esto y del carácter sistémico en el que se mueve este odio racial, de ahí el sentido de sus palabras: "Por eso para nosotros no hay calles, alcantarillados, escuelas ni higiene". Se entiende que el racismo lo padecen los habitantes de Chambacú en su dimensión cotidiana -“¡Negro asqueroso!”- y sistémica.

De igual forma, los pasajes anteriores, en especial el último, entregan pistas sobre los significativos pincelazos del fenómeno del reconocimiento presentes en la novela. En términos generales, el reconocimiento es una necesidad humana vital, por la que los seres humanos están dispuestos a luchar, a entrar en conflictos. Es, para muchos ${ }^{8}$, el verdadero motor de la historia: el problema moral y ético fundamental sobre el que descansan muchos de los problemas de corte económico, político, cultural y psicológico. Para que el reconocimiento sea efectivo tiene que existir una imagen positiva y pública -evidente- del otro, es decir, una

8 Axel Honneth en La lucha por el reconocimiento (1997) y Charles Taylor en El multiculturalismo y "la política del reconocimiento"(1993) son un buen ejemplo. 
comprensión profunda de los conflictos sociales asociados a derechos, estima social y experiencias de respeto e irrespeto. Estos factores tienen el potencial de llevar a una ampliación de la democracia.

El conflicto liderado por un yo crítico, como Máximo, se puede interpretar como un conflicto de carácter ético-moral', como es el caso de la exigencia de reconocimiento hecha por la comunidad de Chambacú y tramitada de forma activa y vehemente por Máximo. En este sentido, frases como "Negro asqueroso", "Tú, un pobre negro" y "El Cáncer negro" son un signo, una señal de la imagen negativa y de la poca estima que la sociedad cartagenera blanca-mestiza le tiene a los habitantes de Chambacú. Como resultado, se da la no construcción de calles, alcantarillados, escuelas y demás necesidades básicas que, al no estar resueltas, los lleva a "ahogarse en la miseria". También, entre otras cosas, trunca los sueños de los deportistas porque el hambre que "les muerde el estómago" trastorna los oídos, hace crujir los dientes, les impide ser campeones y los lleva a un prematuro retiro, como fue el caso de Medialuna, uno de los hermanos de Máximo.

El relato que configura Zapata Olivella en su Chambacú ayuda a comprender que la exclusión por la vía de la ausencia de derechos, el hambre, el desempleo y demás problemas materiales y psicológicos es el resultado de la negación o sustracción de la humanidad del otro. Esto explica uno de los fragmentos más espeluznantes de la novela:

El Capitán contuvo la respiración. "Chambacư". Su pensamiento se polarizaba en esa palabra. Gusto le habría dado prender la mecha a uno de los ranchos de cartón y paja. La brisa del mar. Media hora después, la isla toda ardería. Los negros, sorprendidos, saltarían chamuscados a los caños. El resplandor del incendio ya se asomaba a su cara mestiza. La boca aflautada con la expresión de zorro acorralado. Más afilada la nariz y la arruga en la frente que precedía sus grandes decisiones. "Incendiaré a Chambacú”. Hermosa quema para mirarla desde lo alto de las murallas.

9 Por su temprana adscripción al comunismo (Caicedo 306), se puede interpretar que, en sus primeras novelas -siendo Chambacú, corral de negros una de ellas-, Zapata Olivella comprende los conflictos sociales como motivados por cuestiones materiales (en el Marx de El Capital está presente esta idea). No obstante, el punto en este artículo es mostrar que hay elementos para comprender el conflicto social presente en esta novela como motivado por cuestiones morales (éticas) atinentes al reconocimiento. 
Diez mil casuchas apretadas, todas de paja y papel, rociadas de querosene y coronadas de fuego. Sus tacones machacaron con más fuerza los baldosines. Alcanzaría nuevas presillas. "Coronel". Sonrió (Zapata, Chambacú 38).

Frialdad, insensibilidad, racionalidad instrumental pura son las características con las que Zapata Olivella presenta a un miembro de la policía. Es claro que su mirada hacia Chambacú es cosificante. Los que la habitan son cosas que hay que erradicar bajo el implacable poder del fuego, sus vidas no importan ${ }^{10}$. Chamuscar negros sería un espectáculo digno de ver desde las murallas y que serviría solo para ascender en la policía. En otro pasaje y a través de la voz de otro personaje, Críspulo el gallero, uno de los hermanos de Máximo, Zapata Olivella presenta la imagen negativa de la población afrodescendiente articulada a un contexto más amplio:

Para mí no hay sino Chambacú. Ni siquiera Cartagena. Con lo mal que nos miran. ¿Por qué ha de ir uno a pelear por ellos? Menos servir de burro de carga a los gringos. Si ellos quieren matar chinos y coreanos, será porque algo ganan. Money. Es lo único que les interesa. Esos místeres tampoco saben lo que es democracia. Yo sé que allá cuelgan negros (Zapata, Chambacú 72).

Zapata hace encarnar en Críspulo una conciencia diaspórica. Este personaje tiene la capacidad de ver cómo los afrodescendientes de Colombia y de Estados Unidos son compañeros de tribulación, comparten la experiencia del menosprecio, son valorados de forma negativa por la sociedad a la que pertenecen. Razón por la cual no hay el menor escrúpulo para colocarlos como "carne de cañón" en una guerra ${ }^{11}$ que sentían ajena y carente de justificación legitima. Grandes principios como la demo-

10 Es de destacar la similitud de esta situación de brutalidad policial con el momento histórico que enfrentamos: un contexto de pandemia por una enfermedad llamada COVID-19 o coronavirus. En Estados Unidos y en Colombia, miembros de la policía asesinan a afrodescendientes haciendo uso excesivo de la fuerza. George Floyd, Anderson Arboleda y Janer García. El primero en los Estados Unidos, los dos siguientes en el municipio de Puerto Tejada, Colombia. Hechos que han generado una ola de protestas bajo la consigna: La vida de los negros importa.

11 La guerra a la que se hace referencia es la Guerra de Corea, en la que el gobierno colombiano ordenó a las fuerzas militares reclutar, de forma forzada, hombres para que se unieran al ejército de los EE. UU. (Díaz 244). 
cracia, la libertad, la patria, les resultan falsos y contradictorios frente al menosprecio -"Con lo mal que nos miran"- que viven en Cartagena.

Entre los efectos de la falta del debido reconocimiento está la baja autoestima, problema que se expresa de diferentes formas. Máximo tuvo que lidiar con estas expresiones, no porque él padeciera de baja autoestima, sino porque dentro de la comunidad de Chambacú este problema se había convertido en una tendencia:

El llanto volvió a hurgar la oscuridad como si la noche misma rezongara. Se retiró diluido en la sombra. Siempre entre tinieblas. En la otra, la que ensombrecía la mente de quienes lo rodeaban. El lamento de la madre de Atilio lo perseguía a través de los callejones. Ella pertenecía al bando de los resignados. "Defensor de pobres, mientras yo me muero de hambre". Así pensaba después de las repetidas reuniones en la puerta de su rancho, en que apartada, rumiando el hilo de su tabaco, oía y escupía (Zapata, Chambacú 35).

El tropel del barrio arreciaba, las ancianas rengueaban por los callejones. Buscando el milagro. El puente, las avenidas prometidas. Muchas con caras empolvadas para disimular su pigmento. Algo intuían acerca de que los gringos se asustaban con la piel negra. Ya creían andar por calles pavimentadas (Zapata, Chambacú 219). Mauretania ladraba a las sombras que entraban y salían. El cadáver de Máximo en mitad del patio. Bonifacio metió su dedo sucio en la herida.

— Clotilde, hija mía, nos quedamos solas! Nos lo mataron porque era bueno, porque quería más a los pobres que a su propia madre. [...]

Detrás de la cocina parloteaban las muchachas. Su conversación socavaba la solemnidad de la letanía:

- Yo me voy a hacer la permanente.

- Tu pelo no lo estiran ni con almidón.

- Si yo fuera rubia, como Inge, me lo mandaría a rizar (Zapata, Chambacú 231-232).

Resignación y blanqueamiento como correlato de la baja autoestima, habían hecho metástasis en Chambacú. Dos males que han estado presentes en la historia de la diáspora africana en diferentes contextos, pero que del todo no han logrado contener sus fuerzas. Muchos afrodescendientes, como Máximo, ante el "camino brumoso" de las adversidades y 
la falta de condiciones para una existencia humana digna, han decidido resistir y luchar. Máximo, "el redentor de los pobres", en sintonía con un proceder ya fraguado por referentes históricos afros como Benkos Biojó, pero sin la intención de capitular en algún momento, resiste, lucha con gran vehemencia y se expresa elocuentemente:

—La policía dice que todos los negros tendremos que salir de Chambacú.

-Quieren arrebatarnos lo que hemos alcanzado con sudor y sangre.

-Disque van a construir aquí en la isla un hotel de lujo para los turistas. ¡Así no verán tantos negros mugrosos! [...]

—Nos defenderemos. La Policía comete un atropello. Cumple órdenes de los que se dicen amos de esta isla. [...]

—Dicen que nos darán otras tierras. ¡Mentiras! Siempre prometen. Conocen nuestra generosidad y la explotan al máximo. Saben de nuestra capacidad de sufrimiento y quieren matarnos de hambre. Confunden nuestra paciencia con la resignación. Basta. Resistiremos. Cada rancho será una trinchera. Cada palo un arma. Cada hijo una razón de lucha. Iremos más allá de la resistencia. Exigiremos justicia. Reclamaremos cuanto nos han quitado. Pretenden arrojarnos de estas casuchas que llamamos hogar en vez de darnos lo que nos niegan: trabajo, pan, educación, salud. ¡Organizaremos una marcha sobre la ciudad para reclamar nuestros derechos! (Zapata, Chambacú 183-184).

Elocuentes palabras que parecen revelar el diálogo que Zapata Olivella tuvo con las figuras señeras del discurso de la negritud. Máximo parece estar dotado de esas premisas presentes en la persona de Léopold Sédar Senghor, quien al describir la experiencia diaspórica expresa que su negritud es "paleta en mano y lanza en puño" $(407)^{12}$, es decir, que implica resistencia, rebeldía y defensa, pero también un acto de creación y una propuesta. En Máximo se conjugaba una actitud defensiva y propositiva, de ahí el sentido de sus palabras: "Ir más allá de la resistencia". Máximo, al ser un yo crítico, además de saber traducir las necesidades y las expectativas de su comunidad, brinda esperanza mediante la organización comunitaria de la Junta de Defensa del Barrio. Máximo es un líder

12 Las palabras textuales de Senghor son: "Mi negritud no es un sueño de raza, sino sol del alma [...] Mi negritud es paleta en mano y lanza en puño. [...] Mi trabajo consiste en despertar" (407). 
político genuino, auténtico, sensible, entregado a la causa, convencido de que el camino hacia el cambio positivo para Chambacú no se dará en la medida en que los habitantes se dejen llevar por la resignación o por las promesas de políticos e inversionistas lejanos que dicen querer hacer del territorio de Chambacú un "paraíso". Para Máximo, el cambio se da en la medida en que se constituyan en una fuerza comunitaria, colectiva. Su insistente convocatoria a marchar, su interés en dinamizar el crecimiento de la Junta de Defensa, así lo evidencian. Ideas, acciones que en primera instancia se presentan como poco seductoras, pero que con el trascurso del tiempo van teniendo la recepción debida en otros personajes. Por ejemplo, en Camilo:

- Tengo miedo que te pudras en la cárcel. Estoy muy joven para que me dejes sola. Quiero gozar mi juventud. Además tengo en la barriga un hijo tuyo.

—¿Un hijo?

- Sí, te lo digo antes de que te comprometas con Máximo y la junta. Tienes que dejarte de esas vainas. Tendremos que vivir juntos por nuestro hijo.

— ¡Sí, negra! Ahora, por él, más que nunca debo pelear (Zapata, Chambacú 199).

La búsqueda del cambio como antítesis de resignación, así como la resistencia, la lucha, la organización, la creatividad y el espíritu comunitario son características presentes en la experiencia diaspórica que Zapata Olivella recrea de manera expedida en el desarrollo de su Chambacú, dejando al final un gran mensaje:

Tendido en la cama. La sábana blanca le dejaba el rostro al descubierto. La madre había intentado en vano cerrarle los párpados. [...]

Inge miró su reloj. Las doce. La hora convenida para pintar las consignas. Vio que Clotilde repartía el café en el patio. Estuvo indecisa, no sabía si recordarle o no lo acordado en la Junta, aquella misma mańana. Al levantarse del lado de su suegra, le apretó las manos que sujetaban el rosario. La oyó quejarse sin levantar los ojos. Arrodillada frente a su hijo, le hablaba. Quedó como si apenas le hubiera rasguñado una espuela de gallo:

— ¡Mijo, cuántas veces te lo previne!

Al cruzar la cocina, Dominguito dijo en voz baja a la tía: 
-Camilo y los demás muchachos nos esperan en la escuela de la señorita Domitila. Ya llevo las semillas de aguacate.

La dobladora de tabaco podía cerrar los ojos a Máximo con cuatro puntadas de hilo, pues muchos ya los tenían abiertos (Zapata, Chambacú 233).

Un final de gran valor literario, adornado con una profunda y bella metáfora: Máximo logró cerrar sus ojos, y, a la par, consiguió abrir los ojos de otros, de una nueva generación dispuesta a continuar con la lucha organizada teniendo presente, como lo señala el narrador, que "la lucha por los otros también lo era por sí mismo” (Zapata, Chambacú 185). Zapata Olivella se encarga de mostrar que, al final, la labor de Máximo como "defensor de los pobres", aunque fue trágica - por la forma en que muere a manos del Sargento José Raquel, su hermano- no fue ingrata ni vana, pues la semilla de la insumisión y la esperanza se sembró en buena tierra, es decir, en un puñado de personas cercanas e incómodas con la miseria que los asfixia. Zapata Olivella plasma en estas últimas líneas de Chambacú, corral de negros algo que se infiere en Changó, el gran putas: el bando de los resignados, de los alienados en la experiencia afrodiaspórica, siempre tendrá quien les haga contrapeso, quien abra camino para una existencia más digna y de mayor altura.

\section{Conclusiones}

Chambacú, corral de negros es una valiosa muestra de ese aluvión de insurgencia negra que ha caracterizado parte de la historia de la diáspora africana. En esta novela, Zapata Olivella narra la historia de un barrio de afrocolombianos formado desde principios del siglo XX al lado de las murallas de Cartagena, ciudad símbolo de esclavitud y libertad. En este sentido, Chambacú, corral de negros, más que dejar al descubierto las paradojas sobre las que se ha construido la sociedad cartagenera y colombiana en general, refleja cierta continuidad de la experiencia colonial diaspórica, esto es, el peso del racismo en la vida de los descendientes de los esclavizados.

En muchos diálogos de la novela, las reminiscencias de la esclavitud están presentes. Ellas develan el lugar de enunciación de Zapata Olivella: 
una afrodescendencia que lo constituye, y que, al ser consciente de su existencia, decide que esté en la centralidad de su producción científica y literaria. Por ello, podemos decir que Máximo es el alter ego, es con quien Zapata Olivella, en gran medida, se siente identificado. Máximo es el personaje con el que hace las denuncias de racismo, violencia, miseria, hambre, desigualdad, persecución estatal, intervencionismo de potencias extrajeras, junto a un sinnúmero de problemas que vapulean la existencia de los afrodescendientes y que tienen sus orígenes en "el éxodo africano" (Zapata, Chambacú 190) y en la estructura colonial, que desde el primer día sembró en el continente americano muerte y sufrimiento para los afrodescendientes.

Pero la continuidad de este racismo tiene sus expresiones particulares. En este sentido, Manuel Zapata Olivella deja ver cómo el racismo produce no solo la racialización del otro, sino también del territorio, de la geografía. Por ello, Chambacú en primera instancia es un no lugar, es un lugar de negros, un lugar de fobia. Una vez desacreditado, pasa a ser valorado desde el cálculo instrumental presente en los nuevos proyectos urbanísticos, en donde se habla de desarrollo, pero sin tener presente a las personas, a los seres humanos que domesticaron, formaron y construyeron este espacio. Injusticia que da sustento a lo dicho por Máximo:

Ni siquiera la nación tiene derecho sobre la tierra que pisamos. Bien saben que bajo este basamento de cáscaras de arroz y aserrín sólo hay sudor de negros. No hemos venido acá por nuestra propia voluntad. Nos han echado de todas partes y ahora quieren arrebatarnos la fosa que hemos construido para mal morir (Zapata, Chambacú 184).

Estas palabras evidencian la conciencia que Zapata Olivella tiene de lo que hoy podemos llamar racialización del espacio bajo el cálculo instrumental, a lo cual se antepone el arraigo territorial que los habitantes de la isla habían cultivado como expresión de su voluntad de resistencia. En este punto, nuestro autor entrega elementos para reflexionar sobre un problema que en la década de los ochenta y noventa va a ocupar un lugar central en la agenda política del movimiento social afro en Colombia: la lucha por el territorio. Aunque en este contexto el acento se coloca en lo rural, en Chambacú, la lucha por el territorio se da en un contexto urbano en el que los afrodescendientes también han echado 
raíces: "Afirmaban con la cabeza. Escupían. Los puños apretados. Las palabras los golpeaban de arriba a abajo. Un martinete que les enterraba los pies más profundamente en la isla. Les crecían raíces" (Zapata, Chambacú 184). Este arraigo, por ser cultivado con largas experiencias de sangre, sudor y lágrimas, enseña que la mirada hacia el territorio -en la ciudad o en el campo- trasciende la dimensión de lo material. Esta es una de las enseñanzas que podemos encontrar en esta novela escrita antes de los debates por el territorio presentes en la Ley 70 de $1993^{13}$.

Ahora bien, como se mostró, el tema del reconocimiento atraviesa la novela. Su presencia, aunque indirecta, se infiere, pues se puede interpretar que en la novela la identidad de los habitantes de Chambacú constantemente sufre grandes dańos. No se puede salir ileso de unas dinámicas sociales en donde una de las partes es considerada un "cáncer negro". Esta imagen, como se señaló, es una forma negativa, dañina de valorar a un ser humano y está en estrecha relación con la experiencia colonial y su tozudez de clasificar a los seres humanos por el grado de melanina en su piel. Los efectos psicológicos pueden ser muchos, pero en la novela se destacan aspectos como la fuerte tendencia a resignarse y al blanqueamiento. Estos son solo dos de los muchos problemas que Máximo combate dentro de su comunidad, proponiendo la organización comunitaria como forma de resistencia y afirmación de la procedencia y de la identidad ${ }^{14}$.

Es el espíritu combativo de Máximo frente a los problemas de la comunidad lo que permite concebirlo como un yo crítico, es decir, como un personaje carismático que capta las expectativas frustradas del debido reconocimiento de su comunidad e impulsa un conflicto moral que descansa en la búsqueda de la ampliación de derechos y la estima social que como seres humanos necesitaban los chambaculeros y chambaculeras.

13 Conocida como Ley de Comunidades Negras, mediante la cual, entre otras cosas, se reconoce y se titula el territorio a las comunidades negras de zonas rurales en Colombia.

14 De acuerdo con Marvin A. Lewis (123-124), la resistencia y la afirmación cultural son temas característicos en muchas de las obras de Zapata Olivella, temas que marcan la continuidad en su desarrollo. 
BiBLIOGRAFÍA

Aldana, Ligia. La "négritude" como propuesta de liberación en Chambacú, corral de negros de Manuel Zapata Olivella. Cartagena, Unicarta, 2009.

Arboleda Quiñonez, Santiago. Le han florecido nuevas estrellas al cielo. Suficiencias intimas y clandestinización del pensamiento afrocolombiano. Cali, Poemia, 2016.

Caicedo Ortiz, José Antonio. A mano alzada. Memoria escrita de la diáspora intelectual afrocolombiana. Popayán, Sentipensar, 2013.

CÉsaire, Aimé. Discurso sobre el colonialismo. Madrid, Akal, 2006.

Cunin, Elisabetr. Identidades a flor de piel. Lo "negro" entre apariencias y pertenencias: categorias raciales y mestizaje en Cartagena. Bogotá, ARFO Editores e Impresores Ltda, 2003.

Díaz Granados, José Luis. "Prólogo, apéndices, comentarios y notas". Chambacú, corral de negros. Manuel Zapata Olivella, Bogotá, Educar Editores, 2014, pp. 9-25/235-249.

Honneth, Axel y Nancy Fraser. ¿Redistribución o reconocimiento? Madrid, Ediciones Morata, 2006.

Honneth, Axel. La lucha por el reconocimiento. Barcelona, Crítica, 1997.

Lewis, Marvin A. Literatura Afrocolombiana en sus contextos naturales: Imperialismo ecológico y cimarronaje cultural. Cali, Programa Editorial Universidad del Valle, 2019.

Mina, William. Manuel Zapata Olivella: un legado intercultural. Perspectiva intelectual, literaria y politica de un afrocolombiano cosmopolita. Bogotá, Ediciones desde abajo, 2016.

Ortiz, Lucía. "Chambacú, corral de negros de Manuel Zapata Olivella, un capítulo en la lucha por la libertad. In memoriam". Revista de literatura hispánica, $\mathrm{N}^{\circ}$ 63, 2006, pp. 95-108.

Senghor, Léopold Sédar. Obra poética. Madrid, Cátedra, 1990.

Serna Alonso, Pedro Luis. Narratología cognitiva, Compresiones narrativas en la novela de Manuel Zapata Olivella: En Chimá nace un santo. Bogotá, Editorial Universidad Jorge Tadeo Lozano, 2016.

TAYlor, Charles. El multiculturalismo y "la política del reconocimiento". Ciudad de México, Fondo de Cultura Económica, 1993. 
Valencia Angulo, Luis Ernesto. Negro y afro. La invención de dos formas discursivas. Cali, Editorial Universidad Icesi, 2019.

Valderrama Rentería, Carlos Alberto. "El proyecto anti-racista del mestizaje. Manuel Zapata Olivella”. Revista Visitas al patio, vol. 14, No 1, 2020, pp. 148-165.

Zapata Olivella, Manuel.;Levántate mulato! Por mi raza hablará el espiritu. Cali, Universidad del Valle, 2020. . Chambacú, corral de negros, Bogotá, Educar Editores, 2014. . "Descolonización de la novela histórica latinoamericana". AfroHispanic Review, vol. 25, N 1, 2006, pp. 131-145.

Recepción: 07-06-2020

Aceptación: 31-12-20 